\title{
Study on bonding properties between arc surfacing layers and 1045 steel substrate using pull-lift test method
}

\author{
Xiuming Cheng ${ }^{1}$, Wumu Liu ${ }^{2}$, Fei Huang ${ }^{3}$, Zhenan Ren ${ }^{1}$, and Xinge Zhang, ${ }^{1, *}$ \\ ${ }^{1}$ College of Materials Science and Engineering, Jilin University, Changchun, China 130022 \\ ${ }^{2}$ Full BOSCH Automotive Parts (Changchun) Co., Ltd., Changchun, China 130012 \\ ${ }^{3}$ Engineering Training and Teaching Center, Northeast Electric Power University, Jilin, China 132012
}

Keywords: arc surfacing layer, bonding properties, pull-lift test method, fracture characteristics, microstructure.

\begin{abstract}
Three kinds of surfacing layers of the austenitic steel, niobium alloyed steel and hypereutectic high chromium alloyed cast iron were prepared on 1045 steel substrate by arc surfacing process with self-shielding flux-cored wires. The bonding strength between surfacing layers and the substrate was tested by pull-lift test method. The experimental results show that the bonding strength between austenitic steel surfacing layer and the substrate is the highest up to $549.1 \mathrm{MPa}$, and the fracture location is near the fusion line with quasi-cleavage fracture characteristic. The bonding strength between the surfacing layer of niobium alloyed steel and the substrate is 314.4 MPa and the fracture mainly occurred at the bottom of the surfacing layer, which also presents quasi-cleavage characteristic. While the bonding strength between hypereutectic high chromium alloyed cast iron surfacing layer and the substrate is as low as $170.7 \mathrm{MPa}$ and the specimen ruptures along the fusion line with brittle fracture characteristic. The bonding properties between surfacing layers and the substrate are directly related to the compositions and microstructures near the fusion line.
\end{abstract}

\section{Introduction}

In the cement, electric power, mining and other industrial fields, many equipment parts and components often fail due to fatigue wear, which not only affects the normal work of equipments, but also causes great economic losses. In order to extend the service life of equipments, the wear-resistant surfacing layers are often made on the working surfaces of the parts $[1,2]$. Due to the difference of properties between surfacing layers and substrates, the interface between them often deforms under working loads, and then fatigue cracks initiate and propagate, resulting in local spalling and failure of surfacing layers. Generally speaking, under the same working load, the higher the bonding properties between the surfacing layer

${ }^{*}$ Corresponding author: zhangxinge@jlu.edu.cn 
and the substrate, the better the plasticity and toughness of metals on the interface, and the stronger their ability to resist failure. Because of the advantages of low cost and many kinds of matching between surfacing materials and substrates, the arc surfacing process is widely used in the industrial fields $[3,4]$. Therefore, to test the bonding properties between arc surfacing layers and substrates has the theoretical significance and practical value for predicting the peeling resistance and fatigue resistance of surfacing layers. In terms of the measurement of the bonding properties between surfacing layers and substrates, many measuring methods have been proposed based on different principles and characterization forms [5]. And the common methods include tensile method [6], bending method [7], shear method, etc. [8]. However, most of them focus on the bonding properties between the thin coatings and the substrate, while the measurement methods for the bonding properties between surfacing layers and substrates have been rarely reported. Voutchkov I. et al. [9] designed the push-off test to test the bonding properties between stainless steel layer and low-carbon steel substrate by friction stir surfacing. Peng W.Q. [10] used push-off test to perform the bonding strength between the arc surfacing layers and the substrate. But the fabrication of surfacing specimens was complex, and the bonding area between surfacing layers and the substrate was large, which required the larger push-off force. Therefore, it is necessary to develop a new method to test bonding properties between surfacing layers and substrates.

In this paper, three types of arc surfacing layers were prepared on 1045 steel substrates using the self-shielding flux-cored wire. Drawing on the principle of push-off test, the pull-lift test method was designed to study the bonding properties between arc surfacing layers and the substrate. The bonding properties between three kinds of the arc surfacing layers and 1045 steel substrates were tested and the fracture location and characteristics were observed and analyzed in detail.

\section{Materials and experimental methods}

Three kinds of self-shielding flux-cored welding wires, including austenitic steel, niobium alloyed steel and hypereutectic high chromium alloyed cast iron, were used for arc surfacing experiments. The diameter of all wires was $2.8 \mathrm{~mm}$. The 1045 steel plates were used as substrates, with the dimensions of $200 \mathrm{~mm} \times 120 \mathrm{~mm} \times 25 \mathrm{~mm}$. The Model NBC-630 of inverter welding machine was used as power supply for arc surfacing. Three kinds of surfacing layers were prepared on 1045 steel substrates. The arc surfacing process parameters are shown in Table 1.

Table 1. Arc surfacing process parameters.

\begin{tabular}{ccc}
\hline $\begin{array}{c}\text { Current } \\
I / \mathrm{A}\end{array}$ & $\begin{array}{c}\text { Voltage } \\
\mathrm{U} / \mathrm{V}\end{array}$ & $\begin{array}{c}\text { Surfacing speed } \\
v /\left(\mathrm{cm} \cdot \mathrm{min}^{-1}\right)\end{array}$ \\
\hline 290 & 27 & 18
\end{tabular}

The pull-lift test principle and the specimen are shown in Fig. 1. The pull-lift test specimen is "T" shape and its dimensions are shown in Fig. 1a. The upper part of the specimen is the surfacing layer and the height of the lower part is slightly larger than the substrate thickness. The pull-lift test method and the specimen are beneficial to in-situ observation and analysis after fracture, so as to determine the fracture location and characteristics. Therefore, not only the interface between the surfacing layer and the substrate, namely the "fusion line", is designed at the narrowest position of the specimen, but also the specimen is ground, polished, and etched before the test. The actual specimen is 
shown in Fig. 1b. The pull-lift test is carried out with a tensile testing machine. The specimen is well assembled in the jig, as shown in Fig. 1c. Since the area at the narrowest position of the specimen is the smallest, the tensile stress sustained at this area is the largest. When the pull-lift force exceeds the bearing capacity of the metals on the interface between the surfacing layer and the substrate, the specimen will fracture. The maximum force is recorded and the actual fracture area is measured to obtain the bonding strength between the surfacing layer and the substrate.

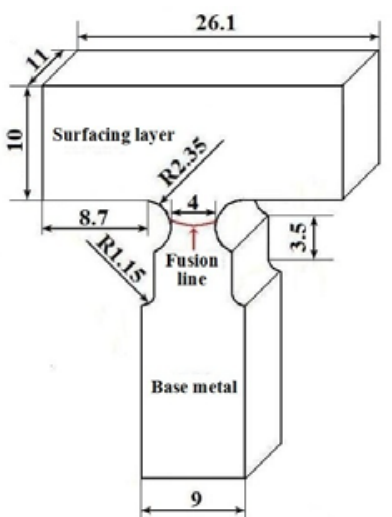

(a) Dimensions of specimen

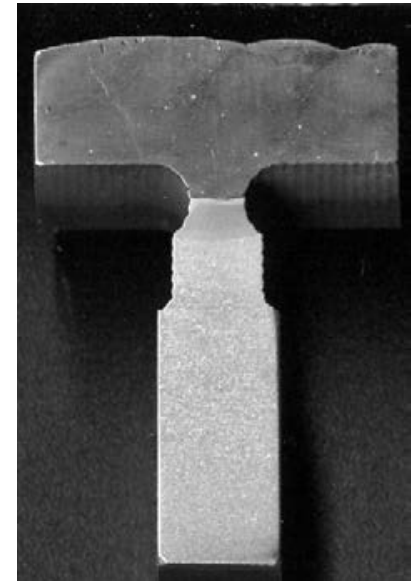

(b) Testing specimen

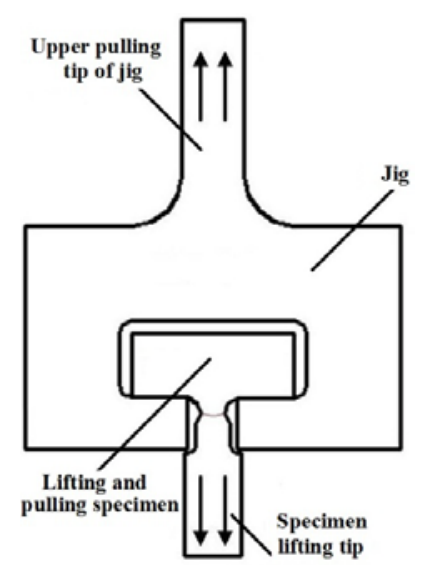

(c) Schematic diagram of pull-lift test

Fig. 1. The schematic diagram of pull-lift test and specimen.

The chemical compositions of the surfacing layers were determined by ARL4460 photoelectric direct reading spectrometer. The pull-lift test specimens were prepared with electric spark cutting according to Fig. 1a, followed by grinding, polishing and etching treatments. The areas around the fusion line and the microstructures of the surfacing layers were observed by optical microscope. The Pull-lift test was carried out by using WQ-4100 tensile testing machine. The fracture characteristics of specimens were analyzed by metallographic microscope and JXA-840 scanning electron microscope (SEM).

\section{Results and discussion}

\subsection{Compositions and microstructures of surfacing layers}

The composition analysis results of the austenitic steel surfaced layer, niobium alloyed steel surfaced layer and hypereutectic high chromium alloyed cast iron surfacing layers are shown in Table 2. The surfacing layer of austenitic steel had highest $\mathrm{Cr}$ content and many austenitic elements such as $\mathrm{Mn}$ and $\mathrm{Ni}$, which microstructures were mainly characterized by large dendritic single-phase austenite. The fusion line contained a thin layer of austenite. Due to the rapid cooling rate, some angular austenite crystals extended into the fusion zone, as shown in Fig. 2a.

The contents of $\mathrm{C}$ and $\mathrm{Nb}$ in the surfacing layer of niobium alloyed steel were high, and $\mathrm{Nb}$ was preferentially combined with $\mathrm{C}$ at high temperature forming dispersed niobium carbide particles. Since there were some $\mathrm{Cr}$ and Mo elements that could increase amount of the retained austenite, the substrate near the surfacing layer was composed of a mixture of martensite and retained austenite, as shown in Fig. 2b. There was an acicular martensite layer in the fusion zone, as well as some smaller and dispersed $\mathrm{NbC}$ particles. 
The contents of $\mathrm{C}$ and $\mathrm{Cr}$ in the surfacing layer of hypereutectic high chromium alloyed cast iron were very high. In the fusion zone, there were gray-black pearlite layer and white austenite layer. Due to the dilution of the substrate, the bottom of the surfacing layer near the fusion line was composed of eutectic/hypoeutectic compositions, and the microstructures were composed of white dendritic austenite and gray eutectic, as shown in Fig.2c. For the three kinds of surfacing layers, the HAZs were mainly composed of proeutectoid ferrite precipitated along grain boundary and coarse pearlite.

Table 2. The surface compositions of the surfacing layers(wt.\%).

\begin{tabular}{cccccccccc}
\hline \multirow{2}{*}{ Types of surfacing layers } & \multicolumn{8}{c}{ Compositions of surfacing layers } \\
\cline { 2 - 9 } & $\mathrm{C}$ & $\mathrm{Si}$ & $\mathrm{Mn}$ & $\mathrm{Cr}$ & $\mathrm{Nb}$ & $\mathrm{Ni}$ & $\mathrm{Mo}$ & $\mathrm{Fe}$ \\
\hline Austenitic steel & 0.10 & 0.73 & 5.72 & 16.68 & -- & 8.62 & -- & $\begin{array}{c}\text { Balanc } \\
\mathrm{e}\end{array}$ \\
$\begin{array}{c}\text { Niobium alloyed steel } \\
\begin{array}{c}\text { Hypereutectic high } \\
\text { chromium alloyed cast } \\
\text { iron }\end{array}\end{array}$ & 1.83 & 0.45 & 0.71 & 5.42 & 12.85 & 0.13 & 1.70 & $\begin{array}{c}\text { Balanc } \\
\mathrm{e}\end{array}$ \\
\hline
\end{tabular}
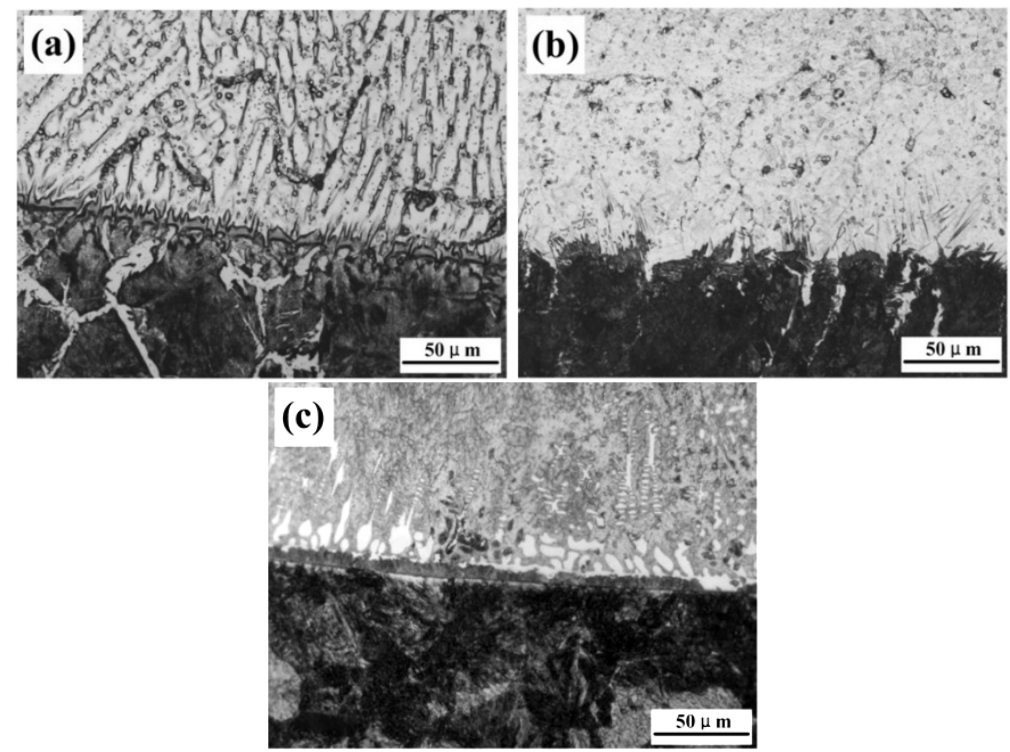

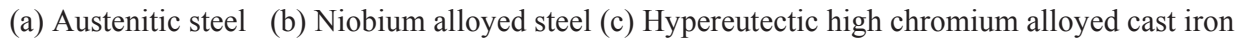

Fig. 2. The microstructures near the interfaces between surfacing layers and the substrate.

\subsection{Bonding strength between surfacing layers and the substrate}

The bonding strength between three surfacing layers and 1045 steel substrate was tested by the pull-lift test method as shown in Fig. 1. The test results are given in Table 3, and the average bonding strengths between 1045 steel substrate and the surfacing layers of austenitic steel, niobium alloyed steel and high-chromium alloyed cast iron are 549.1 MPa, 314.6 MPa and 170.7 $\mathrm{MPa}$, respectively.

During the pull-lift test, the loading area of the interface between the surfacing layer and substrate was small. When the pull-lift load exceeded the bonding strength, the specimen would break at the weakest section of the interface so as to prevent the failure caused by the 
pull-lift fracture in other locations. Therefore, the loading area of the pull-lift specimen was small, and the deformation was small, and then the force-displacement curves of the three types of pull-lift specimens were roughly straight, as shown in Fig.3.The bonding strength was directly related to the microstructures near the fusion line. Since both sides of the interface between the austenitic steel surfacing layer and the substrate were austenite or pearlite with good plasticity and high strength, there was a small amount of deformation at the minimum section of the specimen during the pull-lift test, with the maximum displacement and the highest bonding strength. The austenite in niobium alloyed surfacing layer was beneficial to the bearing capacity of pull-lift specimen, so the pull-lift test curves also showed some displacements, and the bonding strength was medium. However, the hypoeutectic microstructures at the bottom of the surfacing layer of hypereutectic high chromium alloyed cast iron had poor deformation capacity and great brittleness, the bonding strength was the lowest.

Table 3. The bonding strength between surfacing layers and the substrate.

\begin{tabular}{ccccc}
\hline surfacing layer & $\begin{array}{c}\text { Maximum } \\
\text { pull-lift force } \\
\mathrm{KN}\end{array}$ & $\begin{array}{c}\text { Bonding } \\
\text { area } \\
\mathrm{S}, \mathrm{mm}^{2}\end{array}$ & $\begin{array}{c}\text { Bonding } \\
\text { strength } \\
\sigma, \mathrm{MPa}\end{array}$ & $\begin{array}{c}\text { Average bonding } \\
\text { strength } \\
\text { MPa }\end{array}$ \\
\hline Austenitic steel & 20.39 & 39.6 & 513.6 & 549.1 \\
Niobium alloyed steel & 23.15 & 39.6 & 584.6 & 314.6 \\
$\begin{array}{c}\text { Hypereutectic high } \\
\text { chromium alloyed cast }\end{array}$ & 14.97 & 45.3 & 330.5 & \\
iron & 11.77 & 39.4 & 298.7 & 170.7 \\
\hline
\end{tabular}

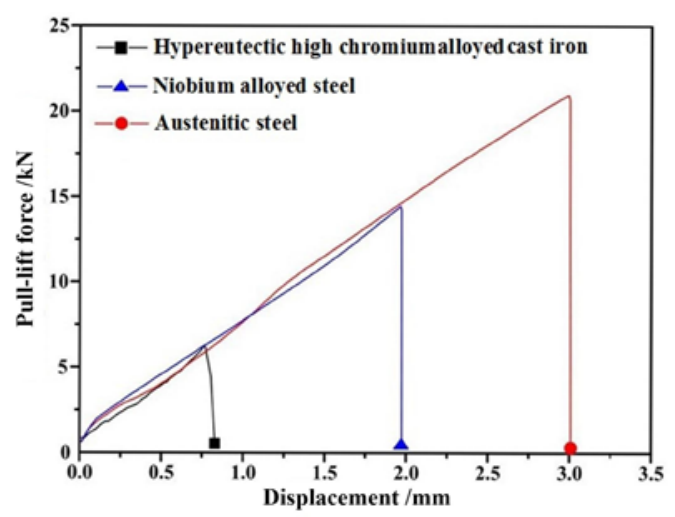

Fig. 3. Typical force-displacement curves of three kinds of pull-lift test specimens.

\subsection{Fracture locations and characteristics}

Fig. 4 shows the fracture location and characteristics of the specimen for austenitic steel surfacing layer using the pull-lift test method. As the surfacing layer was composed of austenite which had high strength and good plasticity, the bonding strength between the surfacing layer and 1045 steel substrate was the highest. By comparing Fig. 4a and Fig. 4b, it could be seen that the specimen ruptured at the narrow fusion zone, and the austenite at the bottom of the surfacing layer and the metal on both sides of the substrate HAZ had obvious deformation. About two-thirds of the left side of the surface ruptured at the bottom of the 
surfacing layer, while about one-third of the right side surface ruptured at the overheat zone of HAZ. Fig. 4c is the SEM fractograph with many dimples, which is ductile fracture.

Fig. 5 shows the fracture location and characteristics of the pull-lift test specimen with niobium alloyed steel surfacing layer. By comparing Fig. 5a and Fig. 5b, most of the specimen for pull-lift test ruptured at the bottom of the surfacing layer and only a small part of the fracture surface was located in the HAZ, with a small amount of deformation resulting from retained austenite mixed structures, and there are some dispersed $\mathrm{NbC}$ particles. The strength of the niobium alloyed steel surfacing layer was significantly lower than that of austenite steel surfacing layer. The SEM fractograph is shown in Fig.5c. The cleavage morphology with few tearing edges and many stepped planar planes could be observed, which was generally quasi-cleavage fracture.

Fig. 6 shows the fracture location and characteristics of the pull-lift test specimen with hypereutectic high chromium alloyed cast iron surfacing layer. According to Fig. 6a and Fig. $6 \mathrm{~b}$, the specimen for pull-lift test ruptured strictly along the fusion line, and the fracture edge was neat without deformation. Due to the existence of the hypoeutectic structures on one side of the surfacing layer, the deformation ability and bonding strength of specimen decreased. As shown in Fig. 6c, it was a typical brittle fracture with strong directional step pattern.
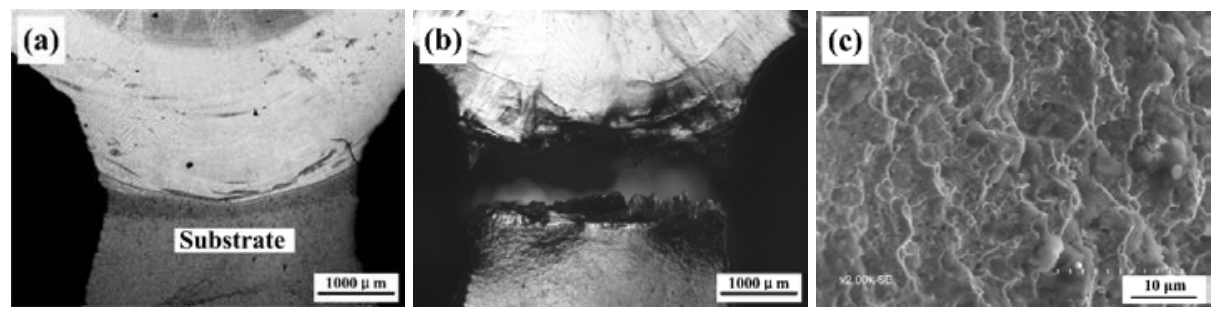

(a) Before pull-lift test(b) After pull-lift test(c) SEM fractograph

Fig. 4. Pull-lift specimen for surfacing layer of austenitic steel and substrate.
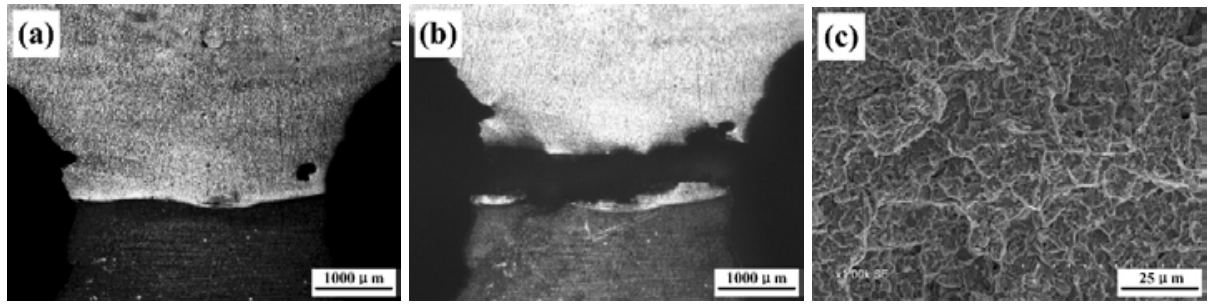

(a) Before pull-lift test(b) After pull-lift test(c) SEM fractograph

Fig. 5. Pull-lift specimen for surfacing layer of niobium alloyed steel and substrate.
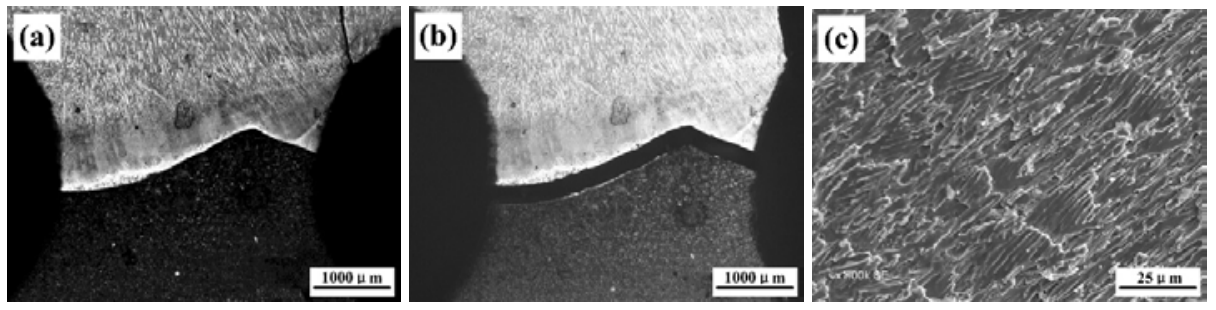

(a) Before pull-lift test(b) After pull-lift test(c) SEM fractograph

Fig. 6 Pull-lift specimen for surfacing layer of hypereutectic high chromium alloyed cast iron and substrate. 


\section{Conclusions}

In present study, three kinds of self-shielding flux-cored wires including austenitic steel, columbium alloyed steel and hypereutectic high chromium alloyed cast iron were used for arc surfacing process. The compositions and microstructures of the surfacing layers were analyzed and observed. The bonding strength between three kinds of surfacing layers and 1045 steel substrate was tested with the pull-lift test method, and the following conclusions were obtained:

(1) The surfacing layer of austenitic steel had high contents of $\mathrm{Cr}, \mathrm{Mn}$ and $\mathrm{Ni}$, and the microstructure was mainly large dendritic austenite. The surfacing layer of niobium alloyed steel had high contents of $\mathrm{C}$ and $\mathrm{Nb}$, which was mainly composed of martensite and retained austenite, and dispersed niobium carbide particles. The surfacing layer of hypereutectic high chromium alloyed cast iron had very high contents of $\mathrm{C}$ and $\mathrm{Cr}$, which was hypereutectic structures composed of primary carbides and eutectic substances.

(2) The average bonding strength between the surfacing layers of austenitic steel, niobium alloyed steel and hypereutectic high chromium alloyed cast iron and 1045 steel substrate was 549.1 MPa, 314.4 MPa and 170.7 MPa, respectively.

(3) The specimen with austenitic steel surfacing layer showed obvious deformation, and the fracture location was at the bottom of the surfacing layer and the HAZ, and then there were many dimples at the fractograph, indicating ductile fracture. The fracture location of the specimen with columbium alloyed steel surfacing layer was mainly ruptured at the bottom of the surfacing layer, and there was a small amount of deformation on both sides of the fracture edge, and then there were few tearing edges and many step-like planes in the fractograph, indicating quasi-cleavage fracture. The specimen with hypereutectic high chromium alloyed cast iron surfacing layer ruptured along the fusion line, and then the fractograph appeared step pattern, which was a typical brittle fracture.

\section{References}

1. J.J. Wei, J. Pan, Z.Q. Huang, J. Xu, X. Wang and Y.S. Zhang. The application of hardfacing material in Chinese cement industry[J]. China Surface Engineering, 2006, 19(3): 9-13.

2. Sapate, S. G. , \& Rao, A. V. R. . (2004). Effect of carbide volume fraction on erosive wear behaviour of hardfacing cast irons. Wear, 256(7-8), 774-786.

3. Amushahi M H , Ashrafizadeh F , Shamanian M . Characterization of boride-rich hardfacing on carbon steel by arc spray and GMAW processes[J]. Surface \& Coatings Technology, 2010, 204(16):2723-2728.

4. Azimi G, Shamanian M . Effects of silicon content on the microstructure and corrosion behavior of $\mathrm{Fe}-\mathrm{Cr}-\mathrm{C}$ hardfacing alloys[J]. Journal of Alloys \& Compounds, 2010, 505(2):598-603.

5. YANG B Q, CHEN G N, ZHANG K, et al. A review on measurement methods for interfacial bonding strength between coating and substrate[J]. Advances in Mechanics, 2007, 37(1): 67-79

6. Shiao M. H, Shieu F.S. Interfacial mechanical properties and fracture morphology of a TiN-coated steel wire upon tensile loading[J]. Thin Solid Films, 2000, 358(1-2):159-165. 
7. Zhang. H, Li. D.Y. Determination of interfacial bonding strength using a cantilever bending method with in situ monitoring acoustic emission[J]. Surface and Coatings Technology. 2002,155(2):190-194.

8. Heinrich G, Horst Weiss. A novel shear test for plasma-sprayed coatings[J]. Surface and Coatings Technology, 1991, 45(1-3):317-321.

9. Voutchkov I., Jaworski B., Vitanov V.I., et al. An integrated approach to friction surfacing process optimisation[J]. Surface and coatings technology, 2001, 141(1): 26-33.

10. PENT W Q. Study on bonding properties between surfacing alloys for cement roller press and the base metal of 45 steel[D]. Changchun Jilin University, 2016 